\title{
К ВОПРОСУ ОБ ОСОБЕННОСТЯХ ОТВЕТСТВЕННОСТИ ЗА НЕИСПОЛНЕНИЕ ИЛИ НЕНАДЛЕЖАЩЕЕ ИСПОЛНЕНИЕ ОБЯЗАТЕЛЬСТВА ПО ДОГОВОРУ ЛИЗИНГА
}

\section{ON THE QUESTION OF THE SPECIFICS OF LIABILITY FOR NON-PERFORMANCE OR IMPROPER PERFORMANCE OF OBLIGATIONS UNDER THE LEASE AGREEMENT}

\section{A. Gudkov \\ A. Krasilschikov \\ V. Mishchenko}

Summary. In this article, the authors, considering the problems of responsibility in the sphere of fulfilling leasing obligations, note that these issues in modern Russian law are relatively incompletely and insufficiently regulated. Paying attention to the fact that in most cases the parties to the lease agreement are entrepreneurs, the authors note that the general basis for their liability under the lease agreement is, first of all, entrepreneurial risk.

According to the authors, the peculiarity of the legal relations under consideration is that the application of general provisions on liability for breach of obligations to leasing does not yet guarantee the restoration of interests affected party, therefore it is important to regulate the use of special methods of protecting violated rights through contractual liability. The authors note that the specificity of the relations under consideration lies in the fact that the lessor is not responsible to the lessee for the actions of the seller under the sale and purchase agreement, except for situations when the lessor chooses the seller himself.

Keywords: leasing, lease, lease agreement, liability, obligation, lessee, lessor.

Б ез преувеличения, можно сказать, что 2020 год в России прошел под знаком борьбы с новой коронавирусной инфекцией и минимизации ее последствий. Потребовалась мобилизация всех сил и средств, с тем чтобы на государственном уровне разработать и реализовать новые правовые механизмы поддержки граждан, ключевых отраслей экономики, малого и среднего бизнеса, совершить разворот медицины на борьбу c COVID - 19.

После вступления в силу поправок в Конституцию РФ по итогам всенародного голосования [1] на заседании

\author{
Гудков Анатолий Иванович \\ К.ю.н., дочент, ВЮИ ФСИН России \\ gudkovaniv@yandex.ru \\ Красильщиков Анатолий Владимирович \\ К.ю.н., дочент, ВЮИ ФСИН России \\ krasilschikov@inbox.ru \\ Мищенко Вячеслав Иванович \\ К.ф.н., дочент, ВЮИ ФСИН России \\ vyacheslav-mischenko@mail.ru
}

Аннотация. В данной статье авторы, рассматривая проблемы ответственности в сфере исполнения лизинговых обязательств, отмечают, что эти вопросы в современном российском праве регламентированы относительно неполно и недостаточно. Обращая внимание на то, что в большинстве случаев сторонами лизингового договора являются предприниматели, авторы отмечают, что общим основанием их ответственности по договору лизинга является, прежде всего, предпринимательский риск.

По мнению авторов, особенность рассматриваемых правоотношений состоит в том, что применение к лизингу общих положений об ответственности за нарушение обязательств ещё не гарантирует восстановление интересов пострадавшей стороны, поэтому важно регламентировать применение особых способов защиты нарушенных прав путем договорной ответственности. Авторы отмечают, что специфика рассматриваемых отношений заключается и в том, что лизингодатель не отвечает перед лизингополучателем за действия продавца по договору купли-продажи, кроме ситуаций, когда лизингодатель сам выбирает продавца.

Ключевые слова: лизинг, аренда, договор лизинга, ответственность, обязательство, лизингополучатель, лизингодатель.

Совета по стратегическому развитию и национальным проектам были скорректированы цели национального развития на период до 2030 года.

И это, по нашему мнению, не отступление от намеченных планов стратегического развития, а конструктивный подход, основанный на трезвом анализе достигнутого уровня социально - экономического развития в беспрецедентных условиях борьбы за каждую человеческую жизнь и сохранения достигнутого уровня социально - экономического развития, жизнеспособности экономики в целом. 
В условиях распространения пандемии коронавирусной инфекции принимались экстренные меры по перепрофилированию медицинских учреждений, строительству новых госпиталей, привлечению врачей общей практики к лечению больных, выделены средства на поддержку семей с детьми, на оказание материальной поддержки системообразующим отраслям экономики и предпринимательскому сообществу, людям старшего поколения, на дополнительные выплаты медицинским работникам.

Уже в конце сентября 2020 года на заседании правительства РФ был принят Общенациональный план действий, обеспечивающих восстановление занятости и доходов населения, рост экономики и долгосрочные структурные изменения в экономике на период до 2024 года. План предусматривает реализацию 500 мероприятий и направлен прежде всего на стабилизацию на рынке труда, которая позволит снизить безработицу, повысить платежеспособность населения. Предусмотрены меры поддержки малого и среднего бизнеса, ускорение технологического развития экономики, увеличение экспорта, поддержку импортозамещения, привлечения инвестиций, улучшение в стране делового климата. На реализацию плана предусмотрено 6,4 трлн. рублей.

В первом квартале 2021 года ситуация в стране с распространением коронавирусной инфекции несколько стабилизировалась,

но по - прежнему характеризуется как сложная. Однако в России, на наш взгляд, созданы правовые и организационные условия, позволяющие минимизировать негативные последствия пандемии и избежать общенационального карантина. Постепенно восстанавливается экономика, выходя на траекторию устойчивого развития. Принят бюджет страны, в котором подтвержден курс на выполнение всех социальных обязательств, возрождается экономика, восстанавливается после серьезного спада активность предпринимательского сообщества.

При этом, безусловно, потребуется обновление и модернизация основных фондов хозяйствующих субъектов, особенно в строительстве, которое продемонстрировало значительный рост благодаря активному использованию россиянами механизмов льготной ипотеки, несмотря на антиковидные ограничения. В этих условиях, на наш взгляд, новый импульс обновлению основных производственных фондов может придать приобретение имущества в лизинг, поскольку он более доступен по сравнению с обычным кредитованием.

Проблематика гражданско-правовой ответственности по договорам аренды в последние десятилетия находится в центре внимания российских цивилистов, позиции которых существенно расходятся. Так, В.В. Витрянский обратил внимание на отсутствие в ГК РФ особых правил, которые бы регулировали ответственность сторон по договору аренды в части его нарушения, либо иных последствий неисполнения, либо ненадлежащего исполнения арендных обязательств [2, с.188]. Иной, противоположной позиции придерживается Е.Е. Ищенко, ссылаясь на положения п. 2 ст. 670 ГК РФ, признавая, однако, их недостаточность.

В Основном законе страны закреплена норма права, гарантирующая каждому возможность свободного использования своих способностей и имущества для предпринимательской и иной, не запрещенной законом экономической деятельности [1]. Исходя из этого, в случае нарушения договора аренды, если конкретным договором не установлены особые правила, стороны придерживаются условий п. 1 гл. 34 и общих положений гражданского законодательства о последствиях неисполнения или либо ненадлежащего исполнения обязательства, содержащихся в гл. 25 ГК РФ.

В отношениях лизинга стороны (арендодатель и лизингополучатель) несут всю полноту ответственности. Они обязаны возместить прямые или косвенные убытки, уплатить штраф при просрочке исполнения обязательств, внести штраф при отказе от исполнения договора лизинга недвижимого имущества, либо его неисполнения. Как и в любом другом договоре, здесь принципиальное значение имеет точное соответствие закону $[3$, c.72].

Заключая договор лизинга, стороны, пусть и имея разный правовой статус, опираются на равные права, учитывая соразмерность возможных штрафов последствиям нарушения. При несоблюдении этого условия суд вправе вмешаться и сократить несоразмерные штрафные санкции

(ст. 333 ГК РФ). Также стороны принимают во внимание обременительную ответственность. Это наличие явной односторонней направленности в пользу стороны договора, недействительность которой может быть установлена по иску потерпевшего (ст. 1 ст. 10 ГК РФ). Такое соглашение также можно признать фиктивной сделкой (ст. 170 ГК РФ), совершенной исключительно для извлечения односторонней выгоды (ст. 168-170 ГК РФ).

Основной гарантией достижения целей лизингового договора следует считать его надлежащее исполнение. При неисполнении или не надлежащем исполнении следует констатировать нарушение договора, которое, как правило, вредит исправной стороне, равно как сложившимся лизинговым отношениям. В целях предотвраще- 
ния нарушений и устранения их последствий в гражданском законодательстве введена гражданско-правовая ответственность. Её параметры формально закреплены в ГК РФ (§ 6 гл. 34), а также в Федеральном законе от 29 октября 1998 г. № 164-Ф3 «О финансовой аренде (лизинге)». В то же время, как уже было отмечено в литературе, указанные акты скорее лишь упоминают, чем в полной мере регулируют указанную ответственность $[4$, c.132].

При нарушении договора лизинга, если невозможно применить специальную норму (либо, когда таковая отсутствует) стороны следуют общим положениям ГК РФ об аренде (§ 1 гл. 34), применимыми и к лизингу, равно как и иными гражданско-правовыми нормами, особенно теми, в которых закреплена ответственность за договорные нарушения.

Подписывая лизинговый договор, стороны свободно определяют параметры и условия ответственности за потенциальные нарушения, невзирая на то, что закон может и не содержать такую ответственность.

Реализуя принцип автономии воли сторон и принцип свободы договора, стороны полномочны самостоятельно определять ответственность, даже если это выходит за рамки, установленные законом. Также стороны вправе сами определять меры и уровни ответственности, пусть и ориентируясь на законодательно закрепленные $[5$, c. 61].

В лизинговые отношения вступают в основном предприниматели. Наступление ответственности для них не предполагает установление вины в несоблюдении обязательств, если иное не закреплено в договоре. Таким образом, общим основанием ответственности по лизинговому договору следует полагать не вину, а предпринимательский риск.

В данном случае, чтобы нарушитель был привлечен к ответственности, необходима совокупность стандартных условий. В частности, ответчик ведет себя противоправно, чем причиняет вред потерпевшему, который от этих действий терпит убытки. При этом между противоправным поведением и наступившими негативными последствиями должна четко прослеживаться причинно-следственная связь.

Специфика лизингового договора, его схожесть с договорами купли-продажи предмета лизинга, позволяют сфокусироваться на специфике ответственности, наступающей за нарушение обязательств. Этот момент показателен в части возложения ответственности на лизингодателя, который, принимая во внимание ст. 670 ГК РФ, не отвечает перед лизингополучателем за исправность
Выполнения продавцом договора купли-продажи. Единственное исключение в данном случае применимо, если сам лизингодатель выбрал продавца. Здесь по закону прослеживается явная связь лизингополучателя с продавцом предмета лизинга. При этом первый, в соответствии с п. 1 ст. 670 ГК РФ, вправе требовать от продавца имущества всё, что указано в договоре купли-продажи, заключенном между продавцом и лизингополучателем. В основном, на практике речь идет о комплектности и качестве товара, соблюдении сроков его поставки.

В данном случае лизингополучатель выступает в роли «простого» покупателя лизингового имущества, хотя, на самом деле его положение иное. Он не брал на себя обязательство тут же оплатить товар, как бы это делал обычный покупатель.

Важно также то, что не требуется согласие лизингодателя, чтобы расторгнуть договор купли-продажи с продавцом. Здесь в пределах отношений с продавцом, другие участники - лизингодатель и лизингополучатель будут считаться солидарными кредиторами.

Учитывая, что с инициативой заключения лизингового договора выступает в основном лизингополучатель, вполне обоснована защита лизингодателя от ответственности. Дело в том, что первый выбирает лизинг как вид приобретения имущества, и он же подыскивает продавца. Действуя рационально, в своих интересах и для своей выгоды, лизингополучатель исходит из личного предпринимательского опыта на рынке, предполагая применить приобретенное также в своей предпринимательской деятельности. Исходя из этого, он не будет действовать себе во вред, необдуманно или опрометчиво, так как имеет интерес в эффективном взаимодействии с контрагентами и приобретении качественного товара.

Отобранное лизингополучателем имущество лизингодатель, также действующий рационально в своих бизнес-интересах, приобретает у проверенного, авторитетного продавца, отвечающего за свой товар. При этом продавец понимает, что его покупатель - лизингодатель не будет сам использовать данное имущество, а передаст его в лизинг. Таким образом, он остается стороной, от которой остальные участники сделки могут требовать возмещения убытков вследствие за ненадлежащего качества товара.

В то же время общее правило, которое освобождает лизингодателя от ответственности, не абсолютно, а имеет ряд исключений. Обратим внимание на п. 2 ст. 670 ГК РФ, в соответствии с которой (когда иное не закреплено в лизинговом договоре), лизингодатель не несет ответственности перед лизингополучателем за исправность 
продавца по договору купли-продажи, кроме ситуации, когда продавец был определен лизингодателем.

Гипотеза данной нормы, содержащая порядок её применения, свидетельствует о диспозитивности, ограничивая освобождение лизингодателя от ответственности при выборе им продавца, что следует оценить, приняв во внимание положения ст. 665 ГК РФ, в соответствии с которым из договора лизинга следует, что выбор продавца товара закреплен за лизингодателем, от которого, как и от продавца (в рамках их солидарной ответственности) лизингополучатель вправе требовать выполнения договора купли-продажи.

Следуя положениям п. 2 ст. 668 ГК РФ лизингодатель несет ответственность за нарушение сроков или порядка передачи имущества лизингополучателю, который в случае просрочки, допущенной лизингодателем, вправе заявить о расторжении договора и требовать возместить понесенные убытки. Такое положение присуще исключительно лизинговому договору, давая возможность лизингодателю заявить о расторжении договора и возмещении убытков, основываясь на факте виновного поведения лизингодателя. Если последний не виноват в сложившейся ситуации, лизингополучатель, действуя в рамках п. 1 ст. 670 ГК РФ, адресует свои требования непосредственно продавцу.

На практике нередко возникает потребность при неисправности лизингодателя информировать лизингополучателя о правах третьих лиц на сам предмет лизинга. Здесь применяется правило, общее для арендных договоров (ст. 613 ГК РФ), когда неисполнение обязанности влечет возникновение права арендатора на уменьшение арендной платы, либо расторжение договора с последующим возмещением убытков.

Насколько приведенные положения применимы к лизинговым отношениям и договору, по которому лизингополучатель свободен в определении приобретаемого имущества и его продавца? Предполагая, что лизингополучатель, действует рационально, ориентируясь на деловой интерес, разумно предположить, что он изучит все качества имущества и именно на этом знании будет базировать свои предпочтения. Обратим внимание, что в специальных нормах § 6 гл. 34 ГК РФ отсутствуют правила, регламентирующие этот аспект, что заставляет применять общие правила об аренде.

Выделяя специфику возложения ответственности на лизингодателя, следует отметить, что вне рамок правового регулирования оказались ситуации, в которых лизингодатель, не соблюдающий свои договорные обязательства, купил пусть качественное имущество, но у иного продавца. Считаем, что такого рода действия следует признать ненадлежащим исполнением договоpa.

Полагаем целесообразным ввести в гл. 34 ГК РФ специальную норму, регулирующую отношения между сторонами при покупке имущества у другого продавца. В данной ситуации лизингополучатель должен получить право отказаться от имущества, составляющего предмет лизинга, а также получить возмещение реальных, понесенных им убытков. Здесь следует исходить из того, что продавца выбрал исключительно лизингодатель, а это указывает на применение п. 2 ст. 670 ГК РФ. Этот подход, по нашему мнению, даст возможность минимизировать случаи ненадлежащего исполнения обязательств и в какой-то мере будет гарантией соблюдения прав лизингополучателя.

Рассмотренная специфика наступления и реализации ответственности лизингополучателя по лизинговым договорам демонстрирует относительно узкий круг возможных нарушений, которые в основном типичны для договорной практики в целом и связаны с неоплатой или задержкой платежей.

Общие положения ГК РФ о лизинге (близкие, по сути, с положениями об аренде) почти не раскрывают эти вопросы. Нельзя отнести к ответственности право лизингодателя на бесспорное списание долга со счёта лизингополучателя, когда последний дважды подряд не внёс платеж (п. 1 ст. 12). Списание лишь возмещает долг, не налагая никаких санкций, и поэтому его нельзя принять за меру ответственности лизингополучателя. В данном случае законодатель предусмотрел скорее лишь меру оперативного воздействия.

Если лизингополучатель не платит вовремя, лизингодатель, не имея на то каких-то особых полномочий, закрепленных нормами права, прибегает к общим положениям ГК РФ об обязательствах и их нарушении. При просрочке платежа, исходя из положений ст. 393 ГК РФ, лизингодатель вправе требовать возмещения убытков, уплаты неустойки, штрафа, пени, что широко используется в предпринимательской практике [6, с.166].

Несвоевременные платежи означают неисполнение денежного обязательства, что помимо указанных выше мер, дает право лизингодателю в соответствии со ст. 395 ГК РФ, взыскивать проценты за пользование чужими деньгами. Следует отметить, что в современных сложных экономических условиях несоблюдение очередности платежей ещё не означает наступление ответственности в виде уплаты процентов. В данном случае необходимо установить факт пользования чужими деньгами, обусловленного неисполнением денежного обязательства, т.е. когда лизингополучатель умышленно удерживает, 
либо израсходовал деньги лизингодателя. Факт пользования деньгами лизингодателя как чужими (ст. 395 ГК РФ) очевиден и когда лизингополучатель не имеет требуемых денег для расчета с лизингодателем, что свидетельствует о невозможности выполнить обязательство. Отсутствие неправомерного пользования чужими деньгами устраняет основания ответственности лизингополучателя.

В заключение отметим, что наука в целом, и наука гражданского права в частности, призвана не только объяснить мир и происходящие в нем процессы в различных сферах жизни общества, но и способствовать преобразованию этого мира, совершенствованию правовых механизмов взаимодействия субъектов граж- данского права в ходе развития и совершенствования усложняющихся социально - экономических реалий, отвечать на новые вызовы времени.

Безусловно, самый совершенный закон не в состоянии учесть и урегулировать все конфликтные ситуации, возникающие между хозяйствующими субъектами. Современный мир развивается стремительно, возникают новые явления, усложняются социально - экономические процессы. Поэтому необходим постоянный анализ причин возникающих правовых споров в ходе реализации действующего законодательства, и при необходимости следует вносить в него изменения, позволяющие гармонизировать интересы государства, общества, граждан, предпринимательского сообщества.

\section{ЛИТЕРАТУРА}

1. Конституция $Р Ф$, принята всенародным голосованием 12 декабря 1993 года (с учетом поправок, внесенных Законами РФ о поправках к Конституции РФ от 30.12.2008 N6-ФК3, от 30.12.2008 N7-ФК3, от 05.02.2014 N2-ФК3, от 21.07.2014 N11-ФК3) // С3 РФ, 14.04.2014, N15, ст. 1691.

2. Бояринова А.О., Шевченко Ю.В., Сайфулова Л.Г. Ответственность за неисполнение и ненадлежащее исполнение обязательства по договору лизинга// Современные научные исследования и разработки. 2017. № 5 (13). С. $71-73$.

3. Григорьева И.М. Некоторые проблемы юридической ответственности за неисполнение или ненадлежащее исполнение обязанностей по договору лизинга// Сегодня и завтра Российской экономики. 2013. № 62. С. 57-64.

4. Витрянский В.В. Договор аренды и его виды: прокат, фрахтование на время, аренда зданий, сооружений и предприятий, лизинг. М.: Статут, 1999. 299 с.

5. Токарева К.Г. К вопросу об ответственности сторон по договору финансовой аренды (лизинга)// Юрисконсульт в строительстве. 2020. № 10. С. 13-137.

6. Беляева И.А. Проблемы правового регулирования ответственности сторон по договору финансовой аренды (лизинга)// Вестник РГгу. Серия «Экономика. Управление. Право». 2008. № 5. С. 162-171. 